CAHIER DE RECHERCHE \#1812E

WORKING PAPER \#1812E

Département de science économique

Department of Economics

Faculté des sciences sociales

Faculty of Social Sciences

Université d'Ottawa

University of Ottawa

\title{
Effects of B.C.’s Carbon Tax on GDP*
}

\author{
Jean-Thomas Bernard, ${ }^{\dagger}$ Misbahul Islam, ${ }^{\ddagger}$ Maral Kichian ${ }^{\S}$
}

November 2018

\footnotetext{
${ }^{*}$ We gratefully acknowledge the financial support of the Social Sciences and Humanities Research Council of Canada. The views expressed in this paper are our own and should not be attributed to the Government of Canada or its staff.

${ }^{\dagger}$ Corresponding author, Department of Economics, University of Ottawa, 120 University Private, Ottawa, Ontario, Canada, K1N 6N5; e-mail: jbernar3@uOttawa.ca.

₹ Government of Canada and Department of Economics, University of Ottawa, 120 University Private, Ottawa, Ontario, Canada, K1N 6N5; email: misla075@uottawa.ca

$\S$ Graduate School of Public and International Affairs, University of Ottawa, 120 University Private, Ottawa, Ontario, Canada, K1N 6N5; e-mail: $\underline{\text { mkichian@uottawa.ca. }}$
} 


\section{Introduction}

The effect of environmental taxes on country GDP is a major policy concern and continues to generate heated debates in public squares. Arguments are presented in support of net positive and of net negative such effects. On the one hand, there is the worry expressed mostly by businesses that environmental taxes can increase costs and thus reduce competitiveness, particularly relative to firms located in countries with less stringent environmental policies. In other words, environmental taxes hurt the economy. On the other hand, there is the double-dividend economic argument whereby environmental taxes not only can reduce negative externalities such as pollution and global warming, but they also can increase income. This prevails if the collected revenues replace those generated by more inefficient taxes such as personal and business income taxes, and particularly if the replacing environmental taxes are revenue-neutral (which ensures no change in the government budget position).

Thus far, there appears to be little or no empirical evidence on the income effect of revenueneutral environmental taxation. This is likely because of the lack of pertinent experience in this respect. Thus although governments of industrialised countries have introduced various forms of environmental taxes in the last three to four decades, these are generally not budget-neutral. In addition, the definition of an environmental tax in these cases is not so clear-cut. Often governments will justify taxes applied to gasoline and to diesel by appealing to environmental considerations, but when these taxes are collected to also expand and maintain roads, they are actually user fees. Similarly, taxes collected in this manner may also serve to fund general government activities. Consequently, such taxes cannot be qualified strictly as environmental levies.

Despite these data shortcomings, researchers have tried to probe the empirical relationship between environmental taxation and the level of economic activity. For instance, Abdullah and Morley 
(2014) use a panel data of OECD countries from 1995 to 2006 and they observe no statistically significant causal effect of an amalgam of various types of 'environmental' taxes on economic growth. They reach the same conclusion when they consider a subset of those taxes that are only applied to gasoline and diesel ${ }^{2}$. In this paper, we study the effect of an environmental tax that is both revenueneutral and purely environmental on overall economic activity. More precisely, we study the impact of the carbon tax of the province of British Columbia (B.C.) of Canada on GDP dynamics in that province.

In 2008, the province of B.C. became one of the first jurisdictions to implement a revenueneutral carbon tax on a broad range of greenhouse gas (GHG) emissions originating from fossil fuel use. The tax rate was set at $\$ 10 /$ tonne of $\mathrm{CO}_{2}$ in July 2008 and then raised by $\$ 5$ in July of every year to reach $\$ 30 /$ tonne in $2012^{3}$, remaining at that level until the end of $2017 .{ }^{4}$ All revenues from the new tax were (and continue to be) returned to individuals and businesses through lower income tax rates and subsidies to low income earners. The two lowest personal income tax rates were decreased to provide a tax cut of $2 \%$ in 2008 , and $5.0 \%$ in 2009 , respectively, on the first $\$ 70,000$ earnings. The general corporate income tax rate was reduced from $12 \%$ to $11 \%$ on July 2008 , and then to $10 \%$ on July 2011 . Similarly, the small business income tax rate was reduced from $4.5 \%$ to $2.5 \%$ over the same period. The income threshold between small businesses and general corporations was lifted from $\$ 400,000$ to $\$ 500,000$. In addition, annual tax credits of $\$ 100$ per adult and $\$ 30$ per child are granted to low income residents.

This unique policy initiative has attracted the attention of applied economists and policy analysts. Studies have been published on the effects of the B.C. carbon tax on gasoline demand in the

\footnotetext{
${ }^{2}$ Abdullah and Morley (2014) use the OECD definition of an environmental tax: it is a per unit tax on a good that has an environmental effect. Gasoline and diesel taxes form by far the largest component of environmental taxes according to the OECD definition.

${ }^{3}$ The tax of $\$ 30 /$ tonne of $\mathrm{CO}_{2}$ is equivalent to $6.83 \$$ /litre of gasoline and $7.68 \mathrm{\phi} /$ litre of diesel.

${ }^{4}$ The tax was increased to $\$ 35 /$ tonne on April1, 2018. Except as otherwise noted, all values are expressed in Canadian dollars.
} 
province $^{5}$, on provincial employment ${ }^{6}$, and on household welfare in the province ${ }^{7}$. However, the effect of the carbon tax on the evolution of the whole economy has received little attention. We focus on this issue in this paper.

Carbon taxes can have several opposite effects on the economy. For households, taxing gasoline, natural gas and other fossil fuels increases the price of most goods and services, and the extent of the price rise depends on the carbon intensity of each of the latter. On the other hand, the lower personal income tax rate resulting from the revenue-neutral design of the tax provides additional incentives to consume and to work. ${ }^{8}$ The relative size of these two opposite effects is specific to each household. Therefore, the overall impact of the carbon tax on the economy due to household reaction is ultimately an empirical question.

The same reasoning applies to firms: higher fuel prices increase costs while lower business income tax rates, given as rebates tied to revenue-neutrality, raise income to equity owners. However, firms differ from one another not only in terms of the energy substitution possibilities available to them, but also with respect to their ability to pass their cost increases onto their prices which are ultimately paid by consumers. The pressure of international trade (whether import or export) puts additional constraints on firm behavior in this respect, and as with households, the effect on the economy is also an empirical question.

We analyze the impacts of the B.C. tax on GDP from two separate perspectives-- those of households versus those of firms -- by considering separately the impacts of gasoline carbon tax and of

\footnotetext{
${ }^{5}$ See Rivers and Schaufele (2015), Antweiler and Gulati (2016), Lawley and Thivierge (2018), and Eruktu and Hildebrand (2018).

6 Yamazaki (2017) and Yip (2018).

7 Beck et al. (2015).

8 Income may also accrue to households through reduced business income tax rates and via the new tax credit to low income earners.
} 
diesel carbon tax on the evolution of GDP in British Columbia. These impacts may differ given that households use the bulk of gasoline that they acquire for road transportation (via light duty vehicles and trucks) whereas diesel is mostly used in commercial operations on and off the road. In 2008, motor gasoline and diesel accounted for $19.2 \%$, and $18.1 \%$, respectively, of $\mathrm{CO}_{2}$ emissions from energy use. ${ }^{9}$

In the literature, a vector autoregression (VAR) specification has generally been used to model the dynamic relationship between oil prices and the economy. ${ }^{10}$ Paying due attention to the possible presence of asymmetric effects, we research the impact of the B.C. gasoline and diesel carbon taxes on GDP change within such a framework. More specifically, we consider the statistical significance of slope coefficient estimates and of impulse responses, as well as of differences between dynamic simulations with and without the carbon tax. Additionally, our VAR specification sheds some light on the carbon tax pass-through onto prices paid by consumers. The extent of B.C. carbon tax pass-through is a topic that has not been addressed in previous studies.

Here are our major findings: (i) the B.C. carbon tax has had no statistically significant overall effect on monthly GDP changes of British Columbia, (ii) this result generally holds whether we consider the experience of households (via the impacts of gasoline price) or that of firms (via the impacts of diesel price), (iii) over time there is complete pass-through of B.C. gasoline and diesel carbon taxes onto prices paid by consumers.

The paper proceeds as follows. In Section 2 we survey the relevant literature. In Section 3 we describe the data. Section 4 presents the analytical framework and the estimation and simulation results. Finally, section 5 concludes.

\footnotetext{
${ }^{9}$ B.C. Ministry of Environment (2010) and Statistics Canada (December 2009)

10 J.D. Hamilton, L. Kilian and their coauthors are major contributors in this field.
} 


\section{Literature Review}

To our knowledge, Elgie and McClay (2013) is the only study published thus far that deals explicitly with the assessment of the empirical impact of the B.C. carbon tax on the evolution of the B.C. economy. These authors use a simple difference-in-difference type approach and observe that, from 2008 to 2011, per capita GHG emissions fell by $10 \%$ in B.C. compared to $1.1 \%$ in the rest of Canada (ROC). At the same time, they observe that per capita GDP shrank only by $0.15 \%$ in B.C. whereas it decreased by $0.25 \%$ in ROC. ${ }^{11}$ They thus conclude that the B.C. carbon tax had no noticeable impact on the province's GDP relative to ROC.

Other papers examine the consequences of the B.C. carbon tax either on household welfare or on labour market conditions in British Columbia. Using a calibrated computable general equilibrium (CGE) model of the B.C. economy, Beck et al. (2015) analyze the distributional impact of the revenueneutral carbon tax by income deciles. Their simulations, run with and without the new tax, yield a very small estimate of aggregate household welfare loss of $0.08 \%{ }^{12}$

Yamazaki (2017) uses an annual data panel of Canada provinces over the period 2007 to 2013 to study the effects of B.C. carbon tax on employment and wage. He estimates that the carbon tax led to a $4.5 \%$ increase in total employment and to a decrease in weekly and hourly wage rate of $4.8 \%$, and $5.4 \%$, respectively. ${ }^{13}$ Since the wage decrease is larger than the employment increase, the negative effect of the B.C. carbon tax on total labor income thus ranges from $0.3 \%$ to $0.9 \%$.

Yip (2018) uses individual data collected from the Canadian monthly labor force survey (LFS) over the period July 2001 to June 2015 in order to probe the effects of the B.C. carbon tax on

\footnotetext{
${ }_{11}$ Per capita consumption of refined petroleum products decreased by $17.4 \%$ in B.C. while it increased by $1.5 \%$ in ROC from $2008 / 09$ to 2012/13. See Elgie and McClay (2013) Table 1.

12 See Beck et al. (2015) Table 8. Hicks equivalent income change is used to measure economic welfare. Their main result is that the BC revenue neutral carbon tax is progressive.

${ }^{13}$ See Yamazaki (2017) Table 8 . He estimates that weekly and hourly wage rates fell by $1.6 \%$ and $1.8 \%$ per $\$ 10 /$ tonne of $\mathrm{CO}^{2} \mathrm{e}$, respectively.
} 
employment. The author estimates that the new tax added 1.2 to 1.3 percentage points to the aggregate unemployment rate; at the same time, however, the study finds no significant effects on weekly working hours and on labor force participation rate. ${ }^{14}$

No firm conclusion can be reached from the four above studies regarding the effect of the B.C. revenue-neutral carbon tax on its economy. Elgie and McClay (2013) and Beck et al. (2015) deal with the whole economy and they arrive at opposite conclusions. Yamazaki (2017) and Yip (2018) focus on labor conditions only, and they arrive at opposite assessments with respect to the effect on employment. ${ }^{15}$ The above studies rely mostly on difference-in-difference frameworks to assess the impact associated with the B.C. carbon tax. We adopt a different methodology: one that is based on time series properties that take explicit account of the dynamic relationships between refined oil product prices, taxes and GDP.

\section{Data}

Our sample consists of monthly series for B.C. from January 1987 to December 2016 on: average prices of diesel and gasoline (regular) that are inclusive of all taxes ( $\mathrm{c} / \mathrm{litre})$, carbon taxes (\$/tonne of $\mathrm{CO} 2$ equivalent emissions), consumer price index (CPI), population, and real gross domestic product (GDP; 2007\$). We also make use of some U.S. monthly data, including the Case-Shiller U.S. National Home Price Index, the U.S. interest rate (3-month treasury bill, constant maturity rate), and US CPI. The Appendix shows the sources of these variables. Gasoline and diesel prices are denoted as total fuel prices when they are inclusive of all taxes. We subtract carbon taxes (expressed in cents/litre) from total prices to obtain net-of-carbon-tax prices. The province's CPI series is applied to both series

\footnotetext{
${ }^{14}$ See Yip (2018) Table 2. He finds that the low and medium educated people are experiencing larger unemployment relative to highly educated people.

15 The negative effect on wage rate estimated by Yamazaki (2017) leads to an overall negative effect on total labor income despite the higher employment.
} 
to obtain their real counterparts. The net-of-carbon-tax real prices are deseasonalized by regressing the series on monthly dummy variables. We obtain deseasonalized total real price series by adding real carbon taxes to the latter series. ${ }^{16}$

Figures 1 and 2 show the evolutions of the series of real carbon taxes and real prices net-ofcarbon-tax over the period of January 2008 to December 2016 for gasoline, and for diesel, respectively. Both prices reach a peak in July 2008 and collapse in the following months; growth resumes in early 2009 and until mid-2014 when prices drop again. Gasoline price change has a standard deviation of 5.52 , which is higher than that of diesel price change at $4.59^{17}$. As for carbon tax, it is much smaller in magnitude relative to price net-of-carbon-tax. It was raised five times from July 2008 to July 2012, and the real series was slowly eroded by inflation.

Figure 3 illustrates the evolution of real GDP per capita from 2008 to 2016; the series drops significantly in the last quarter of 2008 and in the first quarter of 2009 with the start of the Great Recession in Canada, bottoming out towards the end of 2009 and recovering slowly thereafter. It has been rising continually since, albeit with some minor bumps.

\footnotetext{
16 The introduction of the carbon tax and its subsequent changes occurred on July 1st of the relevant years, which de facto creates a seasonal component. However deseasonalization is not desirable since it would eliminate the associated effects entirely, as a consequence of their mechanical spreading out over the year.

${ }^{17}$ Although the evolutions of gasoline and diesel real prices reflect the same underlying world oil price trends, oil price and carbon tax changes are subject to different pass-through for these two refined oil products.
} 
Figure 1

Gasoline price (net-of-carbon tax) and carbon tax (2007థ/litre)
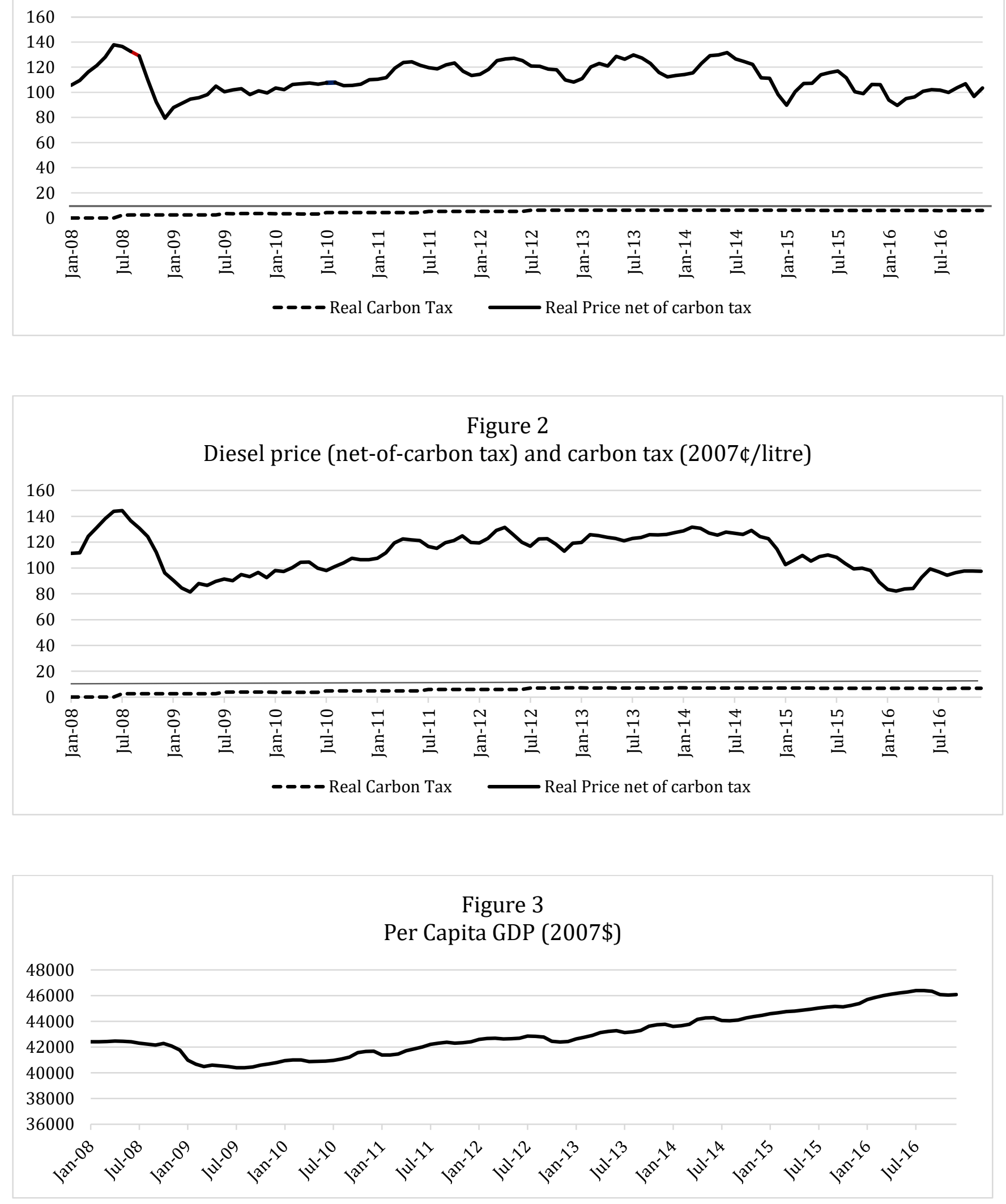
Figure 4 shows that the change in the U.S. real interest rate has been quite volatile over this period. This has been particularly the case during the Great Recession and its aftermath, in line with the decisions and actions of the U.S. Federal Reserve.

Figure 4

U.S. Real Interest Rate (\%)

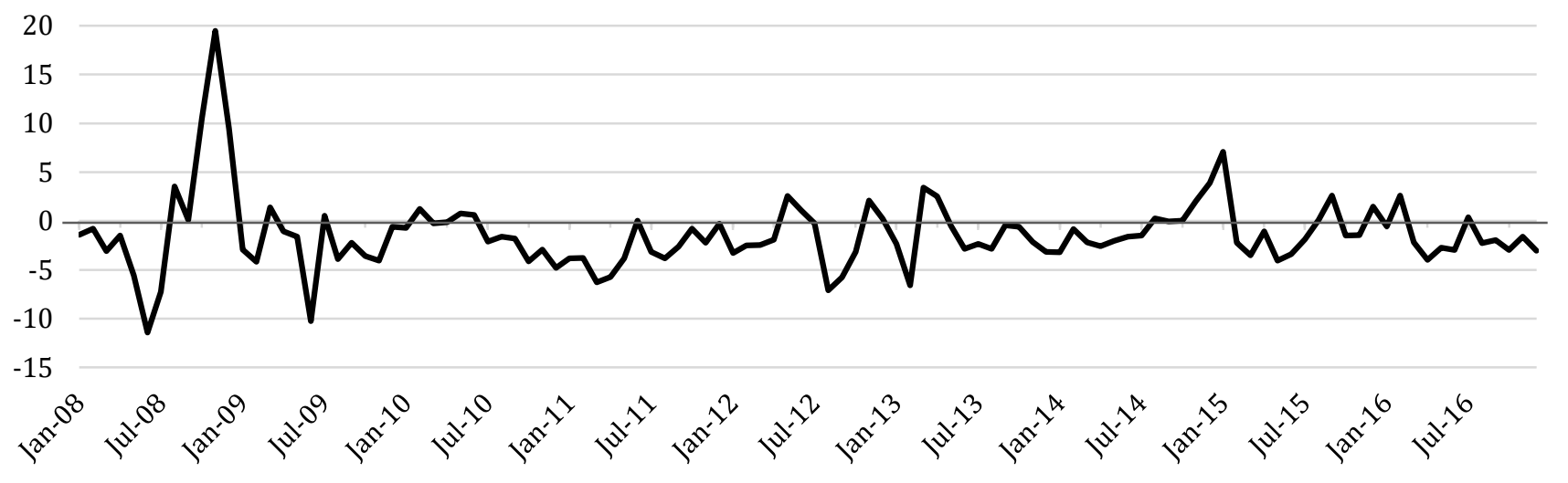

Finally, figure 5 shows the Case-Shiller U.S. National Home Real Price Index. The index level declines continuously until late 2011 , in line with the unfolding of the recession in the U.S. that originated in the subprime mortgage market. It reverts thereafter and continuously increases, mirroring the economic recovery in that country.

Figure 5

Case-Shiller U.S. National Home Real Price Index (2007=100)

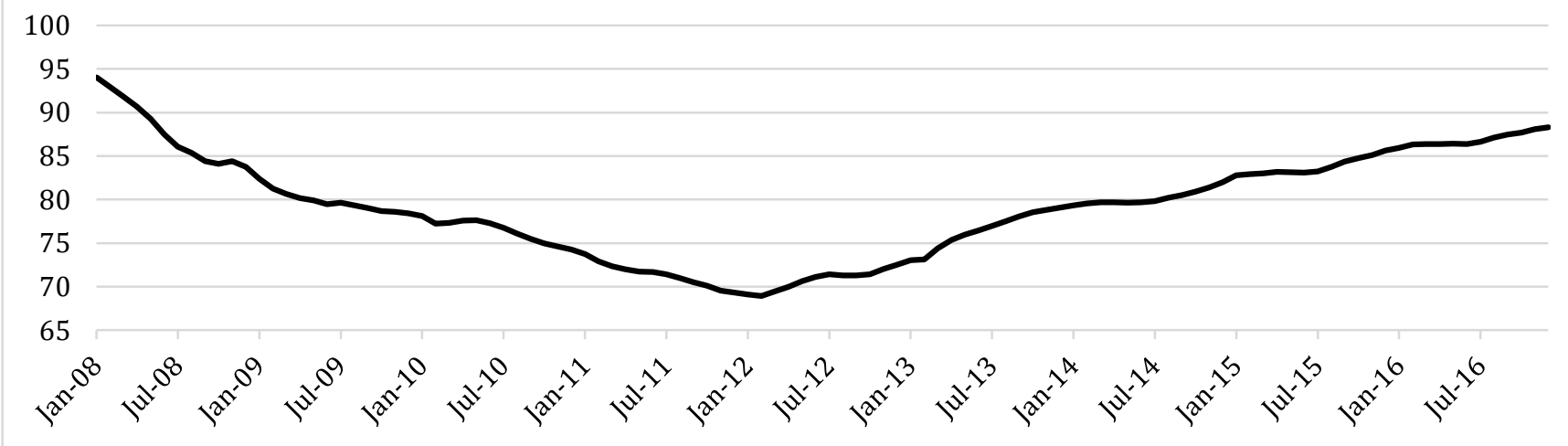


The evolutions of the U.S. variables above thus capture essential aspects of the business cycle dynamics in the U.S. Given the important influence of the U.S. economy on that of Canada (including on the province of British Columbia), they can be used to control for these exogenous impacts on the evolution of Canadian GDP over the period of our analysis.

\section{Model, Estimations and Results}

To analyze the impact of B.C. gasoline or diesel taxes on the province's GDP, we use the modelling strategy proposed by Kilian and Vigfusson (2011). These authors examine the link between crude oil price changes and U.S. GDP growth in the context of a generalized vector autoregression (VAR) framework that can also accommodate various types of oil price asymmetries when they are present in the data. The latter include the possibility that positive changes in oil prices have different effects than negative changes of the same magnitude, as originally proposed by Mork (1989), or, as suggested by Hamilton (1996), who considers that oil price changes that exceed their previously-observed maximum over some given past period generate an additional effect on GDP growth. Hamilton (1996) considers a 1-year span for this time period, while Hamilton (2011) allows for a 3-year window. The model specification is thus given by:

$$
\begin{aligned}
& \Delta \bar{P}_{t}=a_{10}+\sum_{i=1}^{L} a_{11, i} \Delta \bar{P}_{t-i}+\sum_{i=1}^{L} a_{12, i} \Delta y_{t-i}+\varepsilon_{1, t} \\
& \Delta y_{t}=a_{20}+\sum_{i=0}^{L} a_{21, i} \Delta \bar{P}_{t-i}+\sum_{i=1}^{L} a_{22, i} \Delta y_{t-i}+\sum_{i=0}^{L} g_{21, i} \Delta \bar{P}_{t-i}^{\#}+\varepsilon_{2, t},
\end{aligned}
$$

where $\bar{P}_{t}$ is the total price of gasoline or diesel in B.C. inclusive of taxes, $y_{t}$ is per capita GDP in the province, $\Delta$ is the first difference operator, $L$ is the lag order, $a^{\prime}$ s are structural coefficients and $\varepsilon_{j, t}$, $j=1,2$ are error terms. 
The first equation of system (1) can be interpreted as the reduced form of a dynamic model of short run demand and supply equilibrium of a refined-oil product. The price of crude oil, which is determined in the world market, is the main component of oil refined product price. Refinery and distribution margins, which are influenced by local market conditions, are added to oil acquisition costs. In this equation, GDP change is expected to have a positive effect on the total prices of oil refined products. The second equation in system (1) is borrowed from previous studies on the relationships from oil price to the economy. Several factors come into play to determine whether oil price has a positive or negative effect on the economy. For a recent survey, see Degiannakis et al. (2018). A negative impact of rising oil price on GDP change is normally expected in the case of B.C. since the latter is a net importer of oil products. However, this is not necessarily the case here, since there is a positive association between oil price and the prices of raw materials, and since B.C. is a net exporter of raw materials. Furthermore, the B.C. economy is influenced by the economy of its neighbor, Alberta, a large oil-producing province.

The term $\bar{P}_{t}^{\#}$ allows for asymmetric price effects on the economy and it is a censored price series according to the possibilities given by $\bar{P}_{t}^{\#}=\left\{\bar{P}_{t}^{+}, \bar{P}_{t}^{12}, \bar{P}_{t}^{36}\right\}$. The first of these defines $\Delta \bar{P}_{t}^{+}=$ $\max \left\{0, \Delta \bar{P}_{t}\right\}$, implying that price changes are fixed to zero when they are negative. The other two indicators set price changes to zero unless they are the highest observed over the last 12, and 36 months, respectively. Thus, $\Delta \bar{P}_{t}^{12}=\max \left\{0, \bar{P}_{t}-\max \left\{\bar{P}_{t-1}, \ldots, \bar{P}_{t-12}\right\}\right\}$ and $\Delta \bar{P}_{t}^{36}=\max \left\{0, \bar{P}_{t}-\right.$ $\left.\max \left\{\bar{P}_{t-1}, \ldots, \bar{P}_{t-36}\right\}\right\}$

We conduct tests of asymmetry between positive and negative fuel price changes for the above three cases for each of gasoline and diesel prices in British Columbia ${ }^{18}$. The null hypothesis is that no

18 Please refer to Kilian and Vigfusson (2011) for additional test details. 
difference exists between the effects of positive and negative fuel price changes of the same size. Our monthly sample spans the period 1987:1 to $2016: 12$.

Table 1: Tests for Asymmetry

\begin{tabular}{|l|c|c|c|c|c|c|c|c|c|c|c|c|}
\hline & \multicolumn{9}{|c|}{ Gasoline } & \multicolumn{6}{c|}{ Diesel } \\
\hline & \multicolumn{2}{|c|}{$\Delta \bar{P}_{t}^{+}$} & \multicolumn{2}{|c|}{$\Delta \bar{P}_{t}^{12}$} & \multicolumn{2}{|c|}{$\Delta \bar{P}_{t}^{36}$} & \multicolumn{3}{|c|}{$\Delta \bar{P}_{t}^{+}$} & \multicolumn{2}{|c|}{$\Delta \bar{P}_{t}^{12}$} & \multicolumn{2}{|c|}{$\Delta \bar{P}_{t}^{36}$} \\
\hline$h$ & $1 \mathrm{sd}$ & $2 \mathrm{sd}$ & $1 \mathrm{sd}$ & $2 \mathrm{sd}$ & $1 \mathrm{sd}$ & $2 \mathrm{sd}$ & $1 \mathrm{sd}$ & $2 \mathrm{sd}$ & $1 \mathrm{sd}$ & $2 \mathrm{sd}$ & $1 \mathrm{sd}$ & $2 \mathrm{sd}$ \\
\hline 0 & 0.17 & 0.23 & 0.69 & 0.45 & 0.99 & 0.76 & 0.87 & 0.90 & 0.81 & 0.68 & 0.92 & 0.66 \\
\hline 1 & 0.36 & 0.45 & 0.90 & 0.76 & 1.00 & 0.84 & 0.98 & 0.99 & 0.91 & 0.88 & 0.99 & 0.89 \\
\hline 2 & 0.42 & 0.52 & 0.96 & 0.83 & 1.00 & 0.94 & 0.99 & 1.00 & 0.96 & 0.82 & 1.00 & 0.90 \\
\hline 3 & 0.29 & 0.39 & 0.98 & 0.92 & 1.00 & 0.98 & 1.00 & 1.00 & 0.98 & 0.92 & 1.00 & 0.93 \\
\hline 4 & 0.09 & 0.10 & 0.98 & 0.21 & 1.00 & 0.97 & 0.39 & 0.60 & 0.91 & 0.12 & 1.00 & 0.70 \\
\hline 5 & 0.12 & 0.14 & 0.98 & 0.30 & 1.00 & 0.61 & 0.51 & 0.72 & 0.81 & 0.17 & 1.00 & 0.76 \\
\hline 6 & 0.15 & 0.15 & 0.99 & 0.30 & 1.00 & 0.65 & 0.25 & 0.45 & 0.87 & 0.19 & 1.00 & 0.64 \\
\hline 7 & 0.17 & 0.16 & 0.99 & 0.26 & 1.00 & 0.74 & 0.06 & 0.10 & 0.88 & 0.18 & 1.00 & 0.53 \\
\hline 8 & 0.23 & 0.21 & 0.99 & 0.33 & 1.00 & 0.66 & $\mathbf{0 . 0 3}$ & $\mathbf{0 . 0 3}$ & 0.89 & 0.08 & 1.00 & 0.53 \\
\hline 9 & 0.28 & 0.25 & 1.00 & 0.27 & 1.00 & 0.72 & $\mathbf{0 . 0 5}$ & $\mathbf{0 . 0 4}$ & 0.92 & 0.12 & 1.00 & 0.50 \\
\hline 10 & 0.31 & 0.26 & 1.00 & 0.26 & 1.00 & 0.79 & 0.07 & 0.06 & 0.95 & 0.16 & 1.00 & 0.55 \\
\hline 11 & 0.38 & 0.33 & 1.00 & 0.32 & 1.00 & 0.81 & 0.08 & 0.07 & 0.97 & 0.21 & 1.00 & 0.60 \\
\hline 12 & 0.46 & 0.40 & 1.00 & 0.34 & 1.00 & 0.85 & 0.10 & 0.08 & 0.98 & 0.21 & 1.00 & 0.66 \\
\hline 13 & 0.54 & 0.48 & 1.00 & 0.39 & 1.00 & 0.89 & 0.14 & 0.11 & 0.99 & 0.25 & 1.00 & 0.72 \\
\hline 14 & 0.61 & 0.56 & 1.00 & 0.46 & 1.00 & 0.93 & 0.19 & 0.15 & 0.99 & 0.31 & 1.00 & 0.78 \\
\hline 15 & 0.68 & 0.63 & 1.00 & 0.53 & 1.00 & 0.96 & 0.24 & 0.19 & 1.00 & 0.38 & 1.00 & 0.83 \\
\hline
\end{tabular}

Reported numbers are $p$-values. Tests are conducted assuming a VAR model of order 12 . The $p$-values pertain to tests of impulse responses at horizon $h$ assuming a null of symmetry. 1sd refers to an impulse of magnitude 1 standard deviation while 2 sd designates a 2 standard deviation shock.

The results presented in Table 1 show scant evidence of asymmetry in the impact of fuel price shocks on B.C. GDP. The obtained p-values are never below $5 \%$ in the case of gasoline price, and tests are only significant at that level for 4 out of 78 possibilities for diesel price ${ }^{19}$. We thus conclude that the relationship between gasoline and diesel prices and per capita GDP changes in British Columbia can adequately be represented via a standard VAR. In this respect, our conclusions are similar to those

\footnotetext{
19 In 2 of these 4 cases, the evidence for asymmetry arises for the case of a large shock ( 2 standard deviations), and it should be noted that increases in prices due to carbon taxes are considerably smaller in size than even a 1 standard deviation price shock. The carbon tax share of the average diesel price in December 2016 was $6.5 \%$.
} 
reported by Kilian and Vigfusson (2011) and by Karaki (2018), both for U.S. data. The former examines the impact of crude oil price on national GDP growth and the latter studies these same impacts on state unemployment rates. Moreover Kilian and Vigfusson (2013) show that forecast errors obtained by postulating a symmetric VAR model for crude oil and GDP growth are smaller in magnitude than when various asymmetric model options are considered instead.

Based on the above results we therefore conduct our analyses in the context of a symmetric VAR model. We consider several different angles to statistically evaluate the impact of B.C. carbon tax on GDP growth. We first compare impulse responses of B.C. per capita GDP changes to an unexpected gasoline or diesel price shock obtained across the time periods prior to and post carbon taxes ${ }^{20}$. If no difference is observed in the dynamics between GDP change and gasoline/diesel price change across these two time periods, it indicates that the introduction of carbon taxes did not alter the nature of the dynamic relationships between gasoline and diesel prices and the economy in a significant way.

Second, focusing on the time period when carbon taxes are present, we examine the impact of the latter on GDP changes via slope tests. In this case we also account for anticipatory effects, given that the decision to apply such taxes, as well as their timing and pricing details, were publically announced several months prior to the actual implementation of the tax. Although not pertaining to carbon taxes, Coglianese et al. (2017) show that such anticipation effects are present in the U.S. gasoline market. Moreover, commercial users of diesel who rely on large storage facilities make the occurrence of such anticipatory behavior quite likely in the diesel market.

Third, we conduct a counterfactual experiment where we statistically compare the time path of GDP changes obtained in a world with carbon taxes to what that path would have been had no such taxes ever been applied.

\footnotetext{
20 That is, prior to the announcement and the subsequent application of carbon taxes, and the corresponding post period.
} 
A standard VAR model is postulated to undertake our various analyses. The B.C. economy is open, and as a consequence, it is subject to external factors. Our system includes some exogenous U.S. variables to capture these external impacts, notably the Great Recession. This serious recession that originated in the U.S. in 2007 affected Canada primarily over 2008-2009 period, coinciding with the first two years of the carbon tax implementation in B.C., and it is therefore important to disentangle these two effects. We consider lags of the change in U.S. house real price index and in U.S. real short term interest rate as our exogenous variables. The vector $x_{t}$ denotes the levels of these two variables, while $\Delta x_{t}$ represents their first differences. Our VAR model is thus given by:

$$
\begin{aligned}
& \Delta \bar{P}_{t}=b_{10}+\sum_{i=1}^{L} b_{11, i} \Delta \bar{P}_{t-i}+\sum_{i=1}^{L} b_{12, i} \Delta y_{t-i}+\sum_{i=1}^{L *} b_{13, i} \Delta x_{t-i}+e_{1, t} \\
& \Delta y_{t}=b_{20}+\sum_{i=0}^{L} b_{21, i} \Delta \bar{P}_{t-i}+\sum_{i=1}^{L} b_{22, i} \Delta y_{t-i}+\sum_{i=1}^{L *} b_{23, i} \Delta x_{t-i}+e_{2, t} .
\end{aligned}
$$

In the above system of equations, $\bar{P}_{t}$, is total fuel price and thus, includes the carbon tax. That is, $\bar{P}_{t}=$ $\left(P_{t}+T_{t}\right)$, where $P_{t}$ is the real price of gasoline or diesel in B.C. excluding carbon tax, and $T_{t}$ is real carbon tax. Hence, the above system of equations can also be written as:

$$
\begin{aligned}
& \Delta P_{t}=b_{10}+\sum_{i=1}^{L} b_{11, i}\left(\Delta P_{t-i}+\Delta T_{t-i}\right)+\sum_{i=1}^{L} b_{12, i} \Delta y_{t-i}-\Delta T_{t}+\sum_{i}^{L *} b_{13, i} \Delta x_{t-i}+e_{1, t} \\
& \Delta y_{t}=b_{20}+\sum_{i=1}^{L} b_{21, i}\left(\Delta P_{t-i}+\Delta T_{t-i}\right)+\sum_{i=1}^{L} b_{22, i} \Delta y_{t-i}+\sum_{i}^{L *} b_{23, i} \Delta x_{t-i}+e_{2, t}
\end{aligned}
$$

which describes the relationships between the change of gasoline or diesel price, excluding carbon tax and the change of per capita GDP. At this stage, we make two additional assumptions: (i) we allow for the possibility that tax changes may induce larger effects than price changes of the same magnitude, as has been documented in the literature on B.C. gasoline demand by Rivers and Schaufele (2015), Lawley and Thivierge (2018), and Eruktu and Hildebrand (2018). We thus allow tax coefficients to be different from price coefficients in both equations. (ii) We permit anticipated tax changes of up to four months 
to also have impacts, both on GDP changes and on changes in prices excluding carbon taxes ${ }^{21}$. The latter series, while primarily reflective of crude oil prices, also include refinery and distribution margins, and it is possible that the arrival of carbon taxes disrupted those margins. Indeed, in addition to direct carbon tax impacts on GDP, there may be additional indirect effects via adjusted refiner and distributor margins, and it is important to also account for these in measuring overall carbon tax impacts on the economy.

The above considerations lead us to obtain the following general (unconstrained) specification that we use as the framework for our analyses:

$$
\begin{aligned}
& \Delta P_{t}=c_{10}+\sum_{i=1}^{K} c_{11, i} \Delta P_{t-i}+\sum_{i=1}^{K} c_{12, i} \Delta y_{t-i}+\sum_{j=-4}^{4} c_{13, j} \Delta T_{t-j}+\sum_{i}^{L *} c_{14, i} \Delta x_{t-i}+e_{1, t} \\
& \Delta y_{t}=c_{20}+\sum_{i=1}^{K} c_{21, i} \Delta P_{t-i}+\sum_{i=1}^{K} c_{22, i} \Delta y_{t-i}+\sum_{j=-4}^{4} c_{23, j} \Delta T_{t-j}+\sum_{i}^{L *} c_{24, i} \Delta x_{t-i}+e_{2, t} .
\end{aligned}
$$

\subsection{Impulse responses pre- and post- carbon taxes}

The system of equations (2) describing the dynamics between total fuel price and per capita GDP changes is estimated across two sub-periods. The first subsample extends from January 1987 to December 2007 and constitutes the pre-carbon tax years, while the second subsample comprises the era when carbon taxes are present, spanning the period of January 2008 to December $2016^{22}$. For both subsamples we initially consider 12 lags for the endogenous variables and include lags 1 to 24 for the change in US real house price index and lags 6 to 24 for the change in US real short term interest rate. The Bayesian Schwarz criterion is then applied to choose the optimal lag length for the VAR in each subsample and for each fuel type.

\footnotetext{
${ }^{21}$ The provincial government budget of February 2008 first announced the arrival of carbon taxes in British Columbia, along with the schedule of implementations and corresponding prices per tonne of $\mathrm{CO}_{2}$ emissions over the next 5-year period. The first tax application was made in July of 2008.

22 We start the second subsample in January of 2008 to account for any anticipatory effects of the tax.
} 
Figures 6a-b and 7a-b show for gasoline, and for diesel, respectively, the impulse response paths of per capita GDP changes to a one-standard deviation unexpected shock in total fuel price change. In both subsamples, we see that a shock to gasoline price has a significant effect on per capita GDP within the first few months of the shock and that it is insignificant thereafter. This impact is smaller in the earlier subsample and manifests itself in only the third month after the shock, but the sign (which is positive) and the overall dynamics of GDP are largely comparable across the two subsamples.

Figure 6a. Response of GDP to a 1 SD shock to gasoline price:1987:01-2007:12

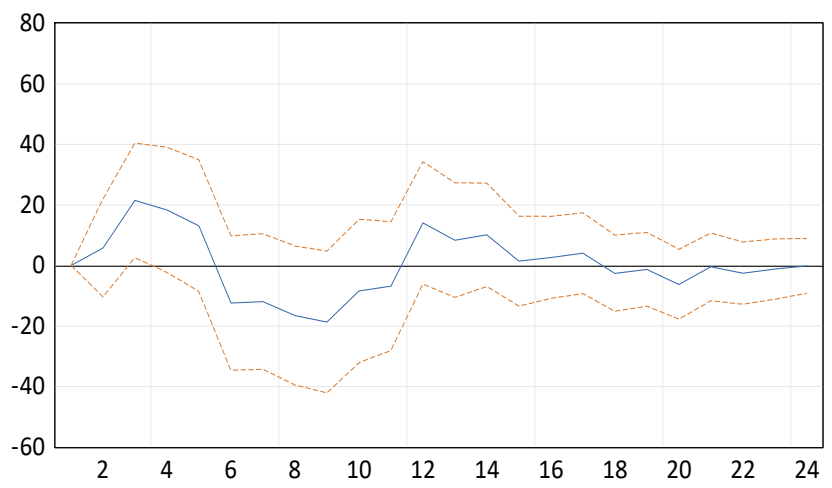

Figure 6b. Response of GDP to a 1 SD shock to gasoline price: 2008:01-2016:12

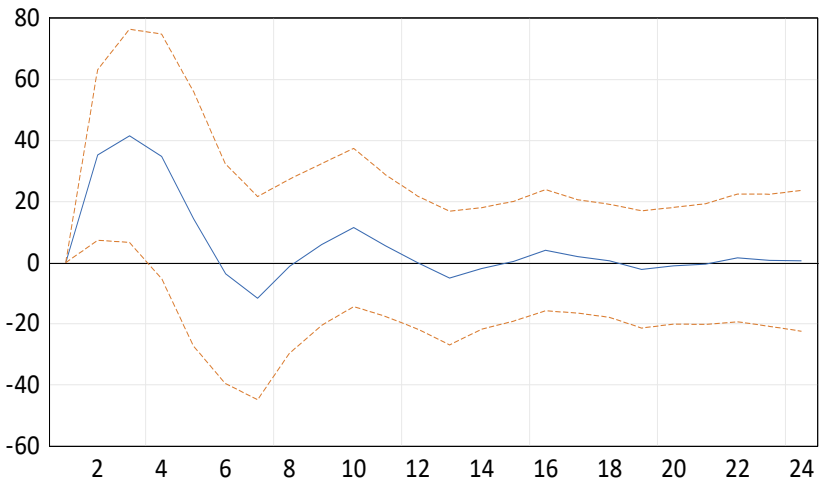

As for diesel, even though the figures appear to be visually different pre and post carbon taxes and the estimated coefficient uncertainty is higher in the second subsample, the GDP impulse response paths are not significantly different in the two sub-periods.

Figure 7a. Response of GDP to a 1 SD shock to diesel price:1987:01-2007:12

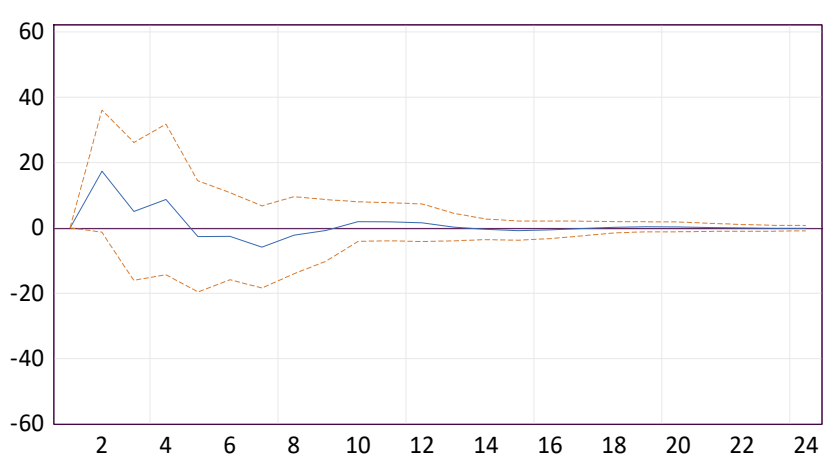

Figure 7b. Response of GDP to a 1 SD shock to diesel price: 2008:01-2016:12

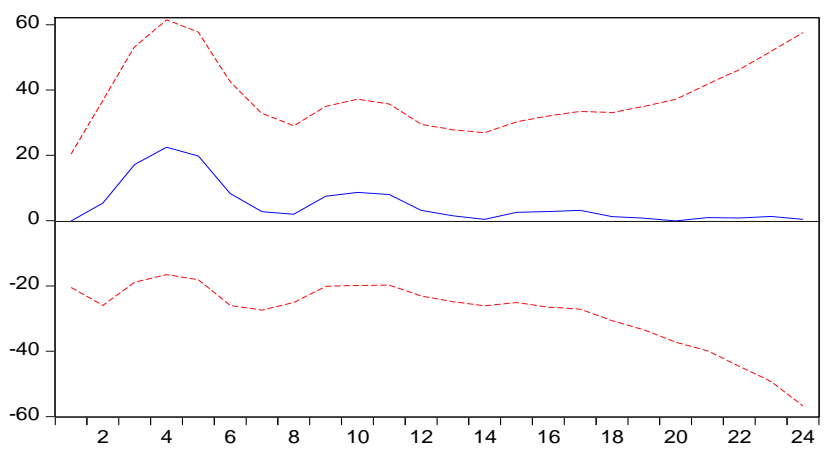


The above results thus show that despite total price including carbon taxes in the latter subsample, the interaction between total price and GDP change for both fuel prices remains essentially similar to that observed prior to the arrival of the carbon tax.

\subsection{Carbon tax impacts using slope tests}

The above inquiry centres on the dynamics between total fuel price and GDP. In this relationship carbon taxes enter indirectly, and the analysis sheds some light on the likely absence of a role of carbon taxes in this regard. In this section, we focus only on the post carbon tax subsample and examine the effects of carbon taxes on GDP directly.

We continue to work with the VAR setup. The general specification allows for 12 lags of the endogenous variables, contemporaneous as well as 4 leads and lags of changes in real carbon taxes (which is exogenous to the system), and, as before, includes lags 1 to 24 of the change in US real house prices and lags 6 to 24 of the change in US real interest rates ${ }^{23}$. The Bayesian criterion is then applied and it selects an optimal lag order of 4 for the VAR when using gasoline price, and 7 when using diesel price.

Estimates of the VAR model (4) are reported in Table 2, along with residual diagnostics. Although only few of the coefficients are significant at the $5 \%$ level, we see that the estimated models present a good fit. In particular, adjusted R-squares are relatively high: for the GDP equations they are 0.59 for gasoline, and 0.72 for diesel; for the price equations these are lower, but this is expected given that it is difficult to forecast fuel prices and that these are often modelled as random walks.

\footnotetext{
${ }^{23}$ We allow the U.S. variables to have an impact on the B.C. economy for up to two years since we observe that the longer lags are individually highly significant. The lags of the change in the U.S. interest rate start at 6 to avoid any possible endogeneity with fuel prices (the latter are largely comprised of crude prices which can influence US interest rates in the short term.)
} 
Table 2: VAR Estimation Results

\begin{tabular}{|c|c|c|c|c|}
\hline & \multicolumn{2}{|c|}{ Gasoline } & \multicolumn{2}{|c|}{ Diesel } \\
\hline & $G D P$ & Price & $G D P$ & Price \\
\hline Constant & $12.24(0.428)$ & $-0.60(0.378)$ & $11.97(0.546)$ & $-0.88(0.340)$ \\
\hline$\Delta P_{t-1}$ & $6.94(0.025)$ & $0.01(0.069) *$ & $0.95(0.789)$ & $0.13(0.427)$ \\
\hline$\Delta P_{t-2}$ & $0.04(0.991)$ & $0.00(0.475)$ & $4.14(0.239)$ & $-0.13(0.437)$ \\
\hline$\Delta P_{t-3}$ & $-0.86(0.793)$ & $0.00(0.299)$ & $-2.61(0.463)$ & $-0.02(0.922)$ \\
\hline$\Delta P_{t-4}$ & $0.83(0.799)$ & $0.00(0.398)$ & $7.89(0.042)^{* *}$ & $0.14(0.424)$ \\
\hline$\Delta P_{t-5}$ & & & $-6.29(0.129)$ & $0.12(0.519)$ \\
\hline$\Delta P_{t-6}$ & & & $-6.56(0.144)$ & $0.04(0.846)$ \\
\hline$\Delta P_{t-7}$ & & & $-1.21(0.773)$ & $0.01(0.955)$ \\
\hline$\Delta y_{t-1}$ & $0.75(0.000) * *$ & $0.04(0.746)$ & $0.78(0.000) * *$ & $0.01(0.118)$ \\
\hline$\Delta y_{t-2}$ & $0.15(0.171)$ & $-0.31(0.034) * *$ & $0.40(0.013) * *$ & $0.00(0.824)$ \\
\hline$\Delta y_{t-3}$ & $-0.80(0.000)^{* *}$ & $0.00(0.997)$ & $-1.43(0.000)^{* *}$ & $0.00(0.813)$ \\
\hline$\Delta y_{t-4}$ & $0.53(0.000) * *$ & $-0.22(0.125)$ & $1.00(0.000) * *$ & $0.01(0.581)$ \\
\hline$\Delta y_{t-5}$ & & & $0.24(0.123)$ & $0.00(0.534)$ \\
\hline$\Delta y_{t-6}$ & & & $-0.72(0.000) * *$ & $-0.01(0.495)$ \\
\hline$\Delta y_{t-7}$ & & & $0.44(0.002) * *$ & $0.00(0.899)$ \\
\hline$\Delta T_{t+4}$ & $23.81(0.602)$ & $2.35(0.244)$ & $24.81(0.499)$ & $3.00(0.083) *$ \\
\hline$\Delta T_{t+3}$ & $5.17(0.914)$ & $-0.02(0.991)$ & $34.73(0.432)$ & $0.61(0.765)$ \\
\hline$\Delta T_{t+2}$ & $7.00(0.884)$ & $2.33(0.272)$ & $-5.96(0.898)$ & $-0.17(0.937)$ \\
\hline$\Delta T_{t+1}$ & 19.19(0.669) & $1.60(0.419)$ & $10.17(0.809)$ & $-0.50(0.800)$ \\
\hline$\Delta T_{t}$ & $42.91(0.356)$ & $-3.57(0.084)^{*}$ & $-31.03(0.462)$ & $-2.85(0.150)$ \\
\hline$\Delta T_{t-1}$ & $-6.85(0.883)$ & $0.28(0.893)$ & $-15.46(0.744)$ & $-2.33(0.292)$ \\
\hline$\Delta T_{t-2}$ & $4.48(0.919)$ & $-1.75(0.368)$ & $40.16(0.376)$ & $-0.79(0.707)$ \\
\hline$\Delta T_{t-3}$ & $84.09(0.058) *$ & $-5.58(0.005)^{* *}$ & $137.42(0.003) * *$ & $-2.12(0.304)$ \\
\hline$\Delta T_{t-4}$ & $-82.01(0.087)^{*}$ & $-5.47(0.011)^{* *}$ & $-133.46(0.006) * *$ & $0.57(0.789)$ \\
\hline$R$-bar square & 0.59 & 0.20 & 0.72 & 0.30 \\
\hline F-Test & $4.15(0.000) * *$ & $1.54(0.057)^{*}$ & $5.07(0.000) * *$ & $1.67(0.046) * *$ \\
\hline Corr(1) Test & \multicolumn{2}{|c|}{$2.66(0.615)$} & \multicolumn{2}{|c|}{$2.45(0.653)$} \\
\hline Corr(4) Test & \multicolumn{2}{|c|}{$0.69(0.952)$} & \multicolumn{2}{|c|}{6.00 (0.199) } \\
\hline Corr(8) Test & \multicolumn{2}{|c|}{$5.71(0.221)$} & \multicolumn{2}{|c|}{$5.86(0.210)$} \\
\hline Corr(12) Test & \multicolumn{2}{|c|}{$4.06(0.397)$} & \multicolumn{2}{|c|}{3.91 (0.419) } \\
\hline Lutkepohl Test & \multicolumn{2}{|c|}{$5.44(0.245)$} & \multicolumn{2}{|c|}{$6.02(0.198)$} \\
\hline
\end{tabular}

Top Panel: reported values are coefficient estimates. Corresponding $p$-values are in parentheses.

Lower Panel: Various tests and their $p$-values. F-test is the Wald test for the joint exclusion of all the regressors in the equation. Corr(j) refers to an LM test for a null hypothesis of no autocorrelation at order $\mathrm{j}$. The Lutkepohl test posits joint normality under the null hypothesis. The coefficients of the U.S. lag variables are included in the estimation but not reported to save space. ${ }^{*}$ implies significance at the $10 \%$ level while ${ }^{* *}$ refers to significance at the $5 \%$ level. 
As for the diagnostic checks on the models, F-tests for the exclusion of the regressors are significant at the $5 \%$ level (except for the gasoline price equation which is significant at $6 \%$ level). In addition, we find no evidence at the $5 \%$ level against the normality of the residuals or against the absence of residual correlation at various lag orders ${ }^{24}$.

Figures 8a-b and 9a-b illustrate visually how fitted changes of the endogenous variables compare with actual changes. It can be observed that the models capture quite well the dynamics of the data over the sample period, notably for GDP (Figures 8a and 9a). In particular, they capture remarkably well the large downturn of the Great Recession and most of the GDP changes until about mid-2014.

Figure 8a: GDP change (2007\$), gasoline

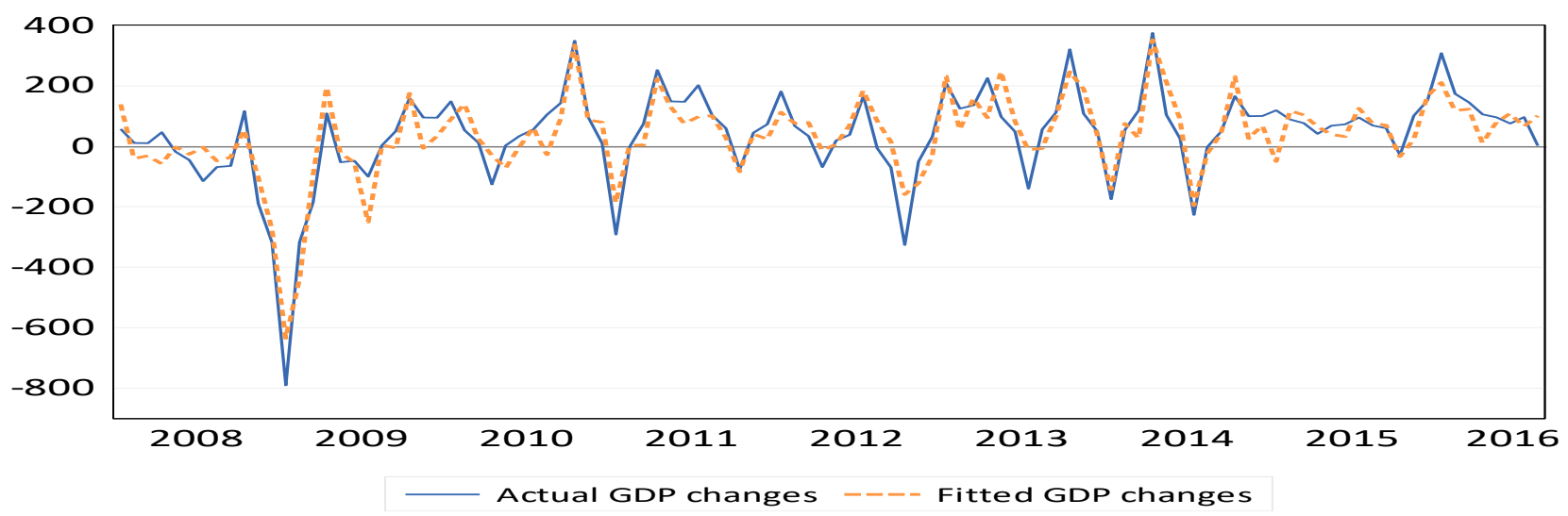

Figure 9a: GDP change (2007\$), diesel

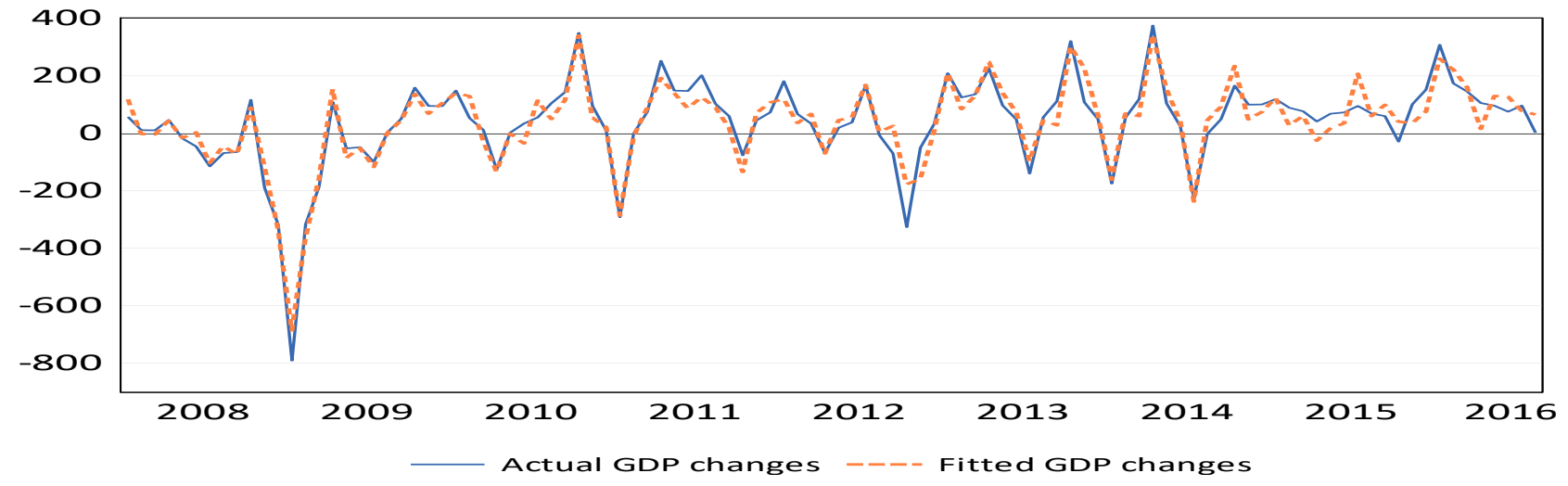

${ }^{24}$ In Table 2 we report selected autocorrelation test results to save space. Full results are available upon request. 
As for the price series, the fit is better in the period before 2013 (which is when carbon taxes were implemented) than after that year, especially for the case of gasoline.

Figure 8b: Price change (2007c/litre), gasoline

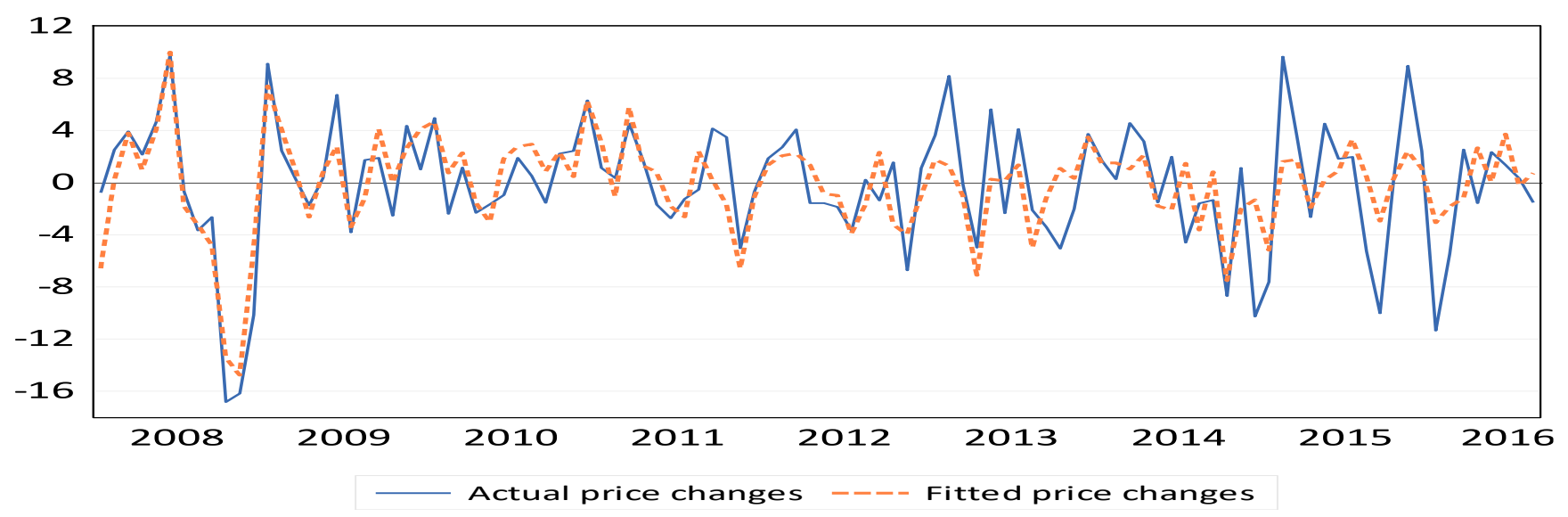

Figure 9b: Price change (2007c/litre), diesel

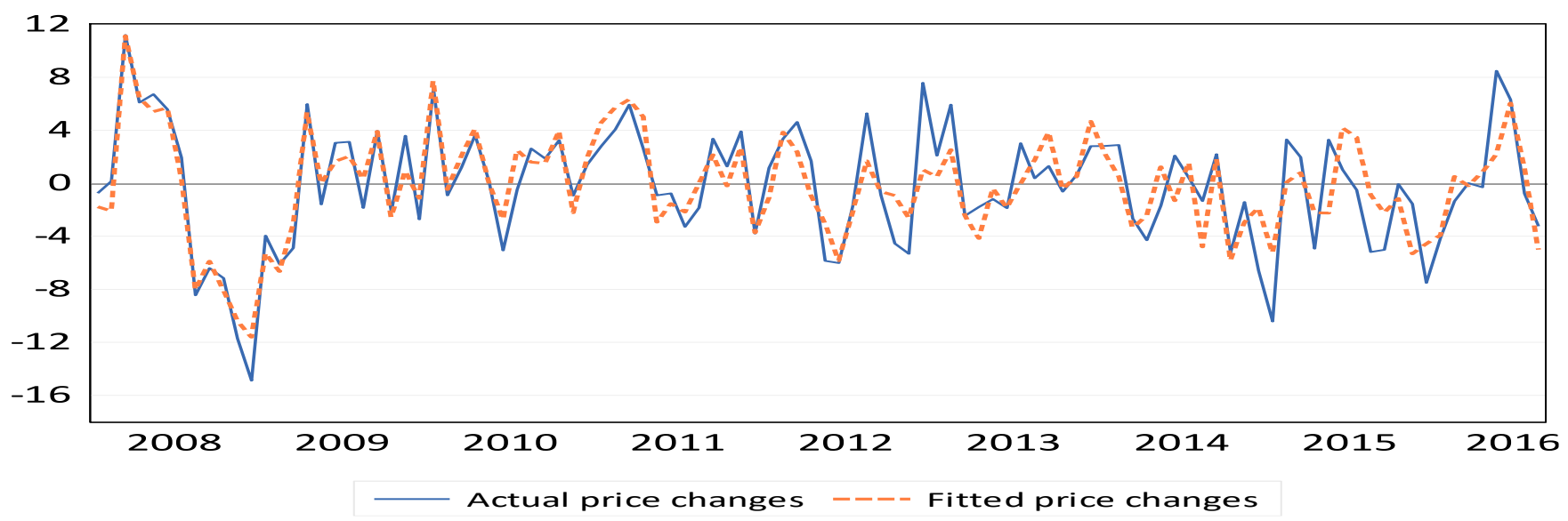

To evaluate the direct impact of the carbon tax on GDP change, we examine the individual coefficient estimates of the carbon tax regressors, as well as their sum. In the former case, we see from Table 2 that only lags 3 and 4 of the carbon tax changes in the diesel VAR model have significant but offsetting impacts on per capita GDP change at the $5 \%$ level; in the gasoline VAR model they are significant at the $10 \%$ level, but they are also offsetting.

As for overall direct carbon tax impacts on GDP, Table 3 summarizes the results for tests of the null hypothesis that the sum of some or all of the carbon tax coefficients is zero (under the heading 
GDP). The results show that, whether for gasoline or for diesel, carbon taxes have no statistically significant effect on GDP changes when we consider the impact of all the included carbon tax changes together. This is also the case when we focus on the joint lags of the carbon tax variable with or without the contemporaneous term, and when we focus on the lead term coefficients.

Table 3: Testing the sum of carbon tax variable coefficients

\begin{tabular}{|c|c|c|c|c|c|}
\hline \multicolumn{2}{|c|}{} & \multicolumn{2}{c|}{ Gasoline } & \multicolumn{2}{c|}{ Diesel } \\
\hline \multicolumn{2}{|c|}{ Tests of: } & $G D P$ & Price & $G D P$ & Price \\
\hline Only lags & $\sum_{j=-4}^{-1} c_{j}$ & $-0.29(0.998)$ & $-\mathbf{1 2 . 5 3 ( 0 . 0 0 1 ) ^ { * * }}$ & $28.65(0.807)$ & $-4.68(0.393)$ \\
\hline Lags + time t & $\sum_{j=-4}^{0} c_{j}$ & $42.61(0.741)$ & $-\mathbf{1 6 . 0 9 ( 0 . 0 0 6 ) * *}$ & $-2.37(0.986)$ & $-7.53(0.238)$ \\
\hline Only leads & $\sum_{j=1}^{4} c_{j}$ & $55.17(0.654)$ & $6.25(0.250)$ & $63.8(0.572)$ & $2.95(0.573)$ \\
\hline All coefficients & $\sum_{j=-4}^{4} c_{j}$ & $97.79(0.651)$ & $-9.85(0.302)$ & $61.4(0.780)$ & $-4.58(0.654)$ \\
\hline
\end{tabular}

Reported values are Wald test F-statistics and corresponding $p$-values in parentheses.

** refers to significance at the $5 \%$ level.

Tables 2 and 3 also shed some light on the extent of carbon tax pass-through onto fuel prices over time. Since gasoline and diesel prices include refinery and distribution margins, it is possible for refiners or distributors to change their margins to adjust to carbon taxes. Under competition, the expectation is that there is complete tax pass-through over time.

Examining individual coefficient estimates from Table 2, we see that lags 3 and 4 of the carbon tax changes have significant negative effects on gasoline price change at the $5 \%$ level; the contemporaneous tax change also has a negative effect although the significance is at the $10 \%$ level. In the case of diesel, we observe a significant positive lead effect of 3 cents/litre of tax change on diesel price change at the $10 \%$ level. Thus there is evidence of limited pass-through in the short run, likely resulting from adjustments in refinery and profit margins. However, when we test the null hypothesis that the sum of all the carbon tax coefficients in these two price equations are zero, we see that the 
null hypothesis cannot be rejected at the $5 \%$ level (see the last row of Table 3 , under the heading Price). The latter indicates full pass-through of carbon taxes over the 9-month test period.

\subsection{Counterfactual Exercises}

The tests conducted so far deal with the direct impacts of carbon taxes. However, in a system of equations with interactions over time amongst the endogenous variables, evaluating the impact of carbon taxes in the context of only one of the two equations would give only a partial idea of these impacts. It is therefore important to complete our analysis in a manner that accounts for these interactions. We do so by conducting a counterfactual experiment where we compare the path of per capita GDP change in a world including carbon taxes against an alternative that excludes such taxes.

Fixing the parameters of the VAR model (i.e., the system of equations (4)) to their estimated coefficients over the 2008:1 to $2016: 12$ period, and using actual values for the exogenous variables over this period, we simulate, for both the gasoline and the diesel VAR cases, the paths of per capita GDP changes, $\Delta y_{t}$, and of price changes, $\Delta P_{t}$, under two scenarios: (i) with changes in real carbon taxes fixed at their actual values over the sample period, and (ii) with changes in real carbon taxes fixed at zero throughout the sample. Under the first scenario, the computed GDP and price changes are denoted $\widehat{\Delta y}_{t}$ and $\widehat{\Delta P}_{t}$, while under the second scenario, they are denoted $\ddot{y}_{t}$ and $\ddot{P}_{t}$. The simulated paths start in January 2008 and end in August 2016. ${ }^{25}$

Figure 10a shows the evolution of per capita GDP change under the scenarios (i) and (ii) for gasoline, along with the estimated $95 \%$ confidence intervals $(\mathrm{Cl})$ generated allowing for the actual evolution of real carbon taxes over the same time period. We find that there are only minor differences between the paths of GDP changes in the presence and in the absence of carbon taxes. More

\footnotetext{
25 The simulation sample ends at this point since the model makes use of 4 leads of carbon taxes.
} 
importantly, the GDP path assuming no carbon taxes, $\Delta \ddot{y}_{t}$, falls well within the $95 \%$ confidence bands of the path obtained allowing for the presence of these taxes, $\widehat{\Delta y}_{t}$.

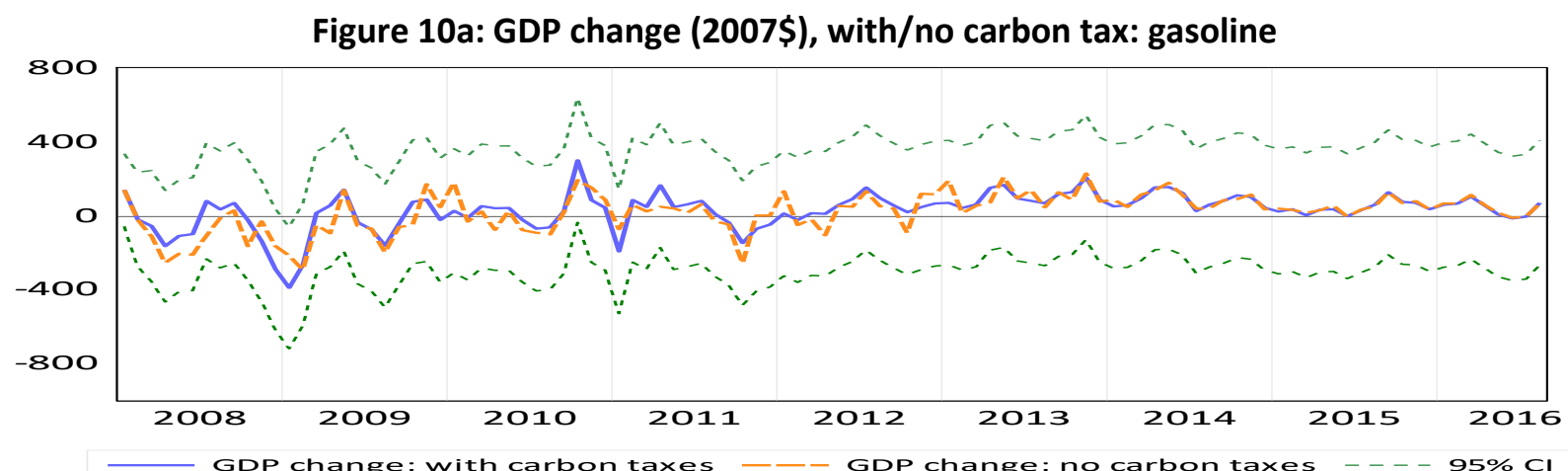

Figure 11a: GDP change (2007\$), with/no carbon tax: diesel

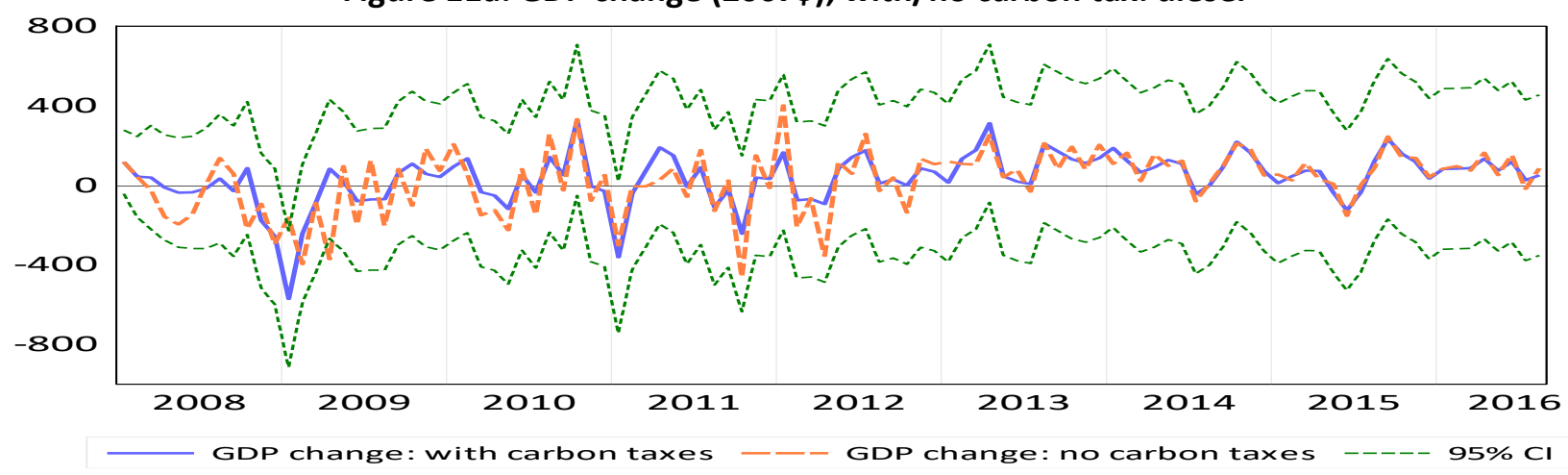

Figure 11a shows the corresponding series for the diesel case. We see again that the path of GDP changes in the absence of carbon taxes generally falls within the $95 \%$ confidence bands of the path obtained allowing for these taxes. Two instances in time present an exception although these largely offset one another: had there been no carbon taxes, in January 2009 the GDP change would have been less negative, and in April 2009 it would have been positive instead of being negative.

Thus despite some differences in the short term in the dynamics of carbon tax for gasoline and diesel prices, and having taken into account all time interactions between endogenous and exogenous variables in the system, we can conclude that carbon taxes generally do not significantly affect GDP 
either in the short run or in the long run (the latter comprises a period of 9 years). This is the case whether we base our analysis on gasoline or diesel price interactions with GDP.

Finally, Figures $10 \mathrm{~b}$ and $11 \mathrm{~b}$ plot the simulated price paths $\widehat{\Delta P}_{t}$ and $\Delta \ddot{P}_{t}$ for gasoline, and diesel, respectively, along with the $95 \%$ confidence intervals obtained for $\widehat{\Delta P}_{t}$. The comparison allows us to evaluate statistically whether, having taken all dynamic interactions amongst variables into account, pass-through of carbon tax has been complete or not.

Figure 10b: Price change (2007c/litre), with/no carbon tax: gasoline

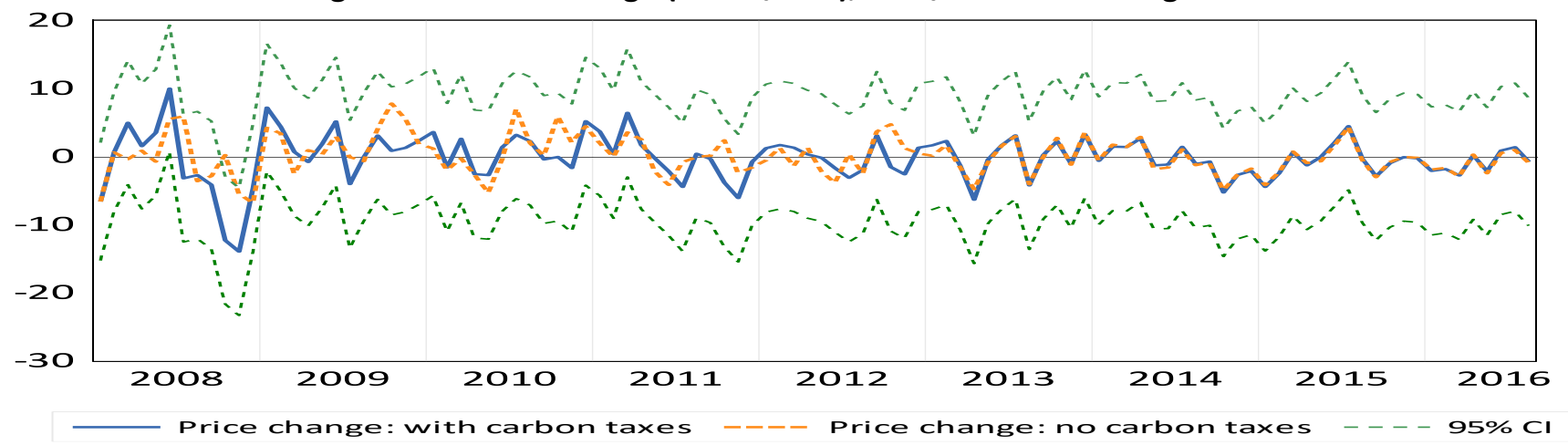

In the case of gasoline price, we find that there is a two-month episode, namely in 2008:10-11, where the $\Delta \ddot{P}_{t}$ series exceeds the upper $95 \% \mathrm{Cl}$ bound for $\widehat{\Delta P}_{t}$, indicating that prices are lower with carbon taxes than they would have been without them. Thus, some minor negative tax incidences likely occurred in the short run on refinery and distribution margins.

Figure 11b: Price change (2007c/litre), with/no carbon tax: diesel

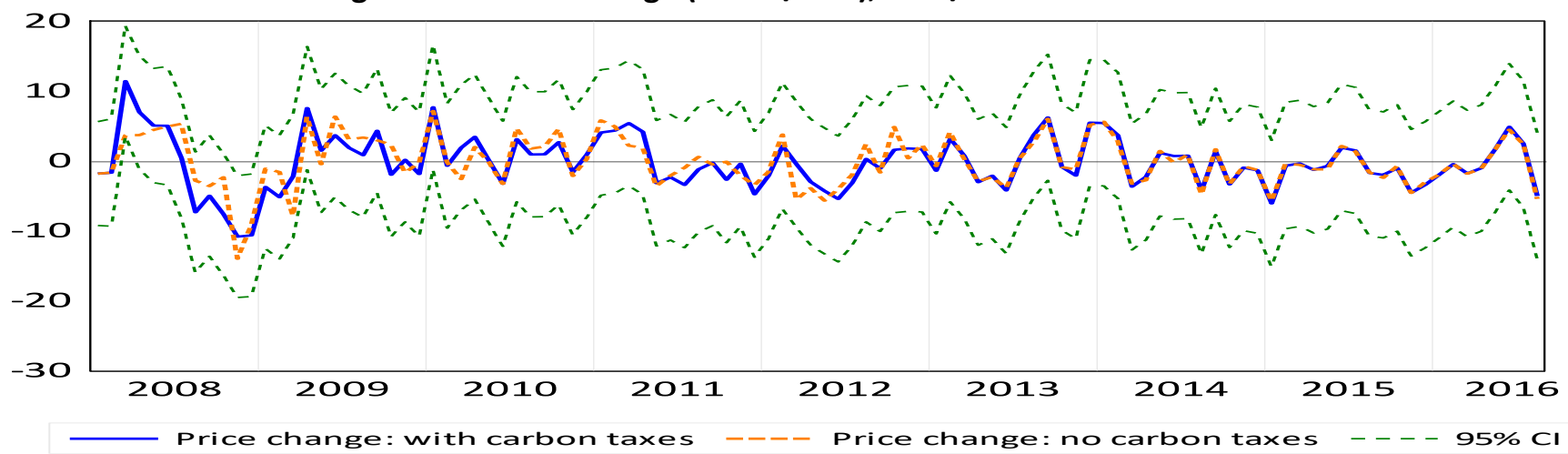


In the case of diesel price, we find no significant difference in the price paths with or without carbon tax. These results support the proposition that carbon tax pass-through has been complete over time, a result that is expected under competition.

\section{Conclusion}

Environmental taxes have been implemented in various forms by several industrialised countries during the last three to four decades and the impact of such taxes on country GDP is a major policy concern. There is little empirical evidence that bears directly on this contentious issue. The introduction of a broad-based revenue-neutral carbon tax by the government of the province of British Columbia in 2008 and in the following years provides a natural experience in this respect. Using a VAR framework and considering the impact of carbon tax on gasoline and diesel prices, we find no difference in the dynamic relationship between the prices of these two oil refined products and per capita GDP changes before and after the introduction of the carbon tax. When we then focus only on the period when the carbon tax was present, and whether we consider slope coefficient estimates or dynamic simulation runs with and without carbon tax, again we find no significant overall impacts of carbon taxes on per capita GDP changes.

We should nevertheless note that our study deals with only a subset of the fossil fuels that are subject to carbon taxation in B.C. (gasoline and diesel accounted for close to $40.0 \%$ of all fossil fuel emissions in 2008). Natural gas, coal, other oil products, natural gas liquids and leaks from fossil fuel production and transportation account for the remaining $\mathrm{CO} 2$ emissions. It is possible that the carbon taxation of these other fuels may have had an impact on the economy. Two major difficulties limit the 
extension of our analysis to these other fuels: first, monthly price data are not available, and second, the share of the carbon tax in the final prices of these fuel products show large differences ${ }^{26}$.

Finally, our finding of no significant effect of carbon prices on per capita GDP change should be interpreted as only a lower bound estimate since additional changes in the spirit of the so-called Porter hypothesis, if they exist, would yield additional positive benefits for the economy but over horizons that extend beyond our analysis period. The Porter hypothesis (Porter and van der Linde (1995)) contends that environmental taxes and regulations can spur innovation, which in turn leads to gains in productivity thus also accelerating growth. Such positive impacts are likely to be both spread out over time and to evolve at fairly long horizons ${ }^{27}$. Future work should be able to examine for the presence of such effects for the B.C. carbon tax as more data becomes available.

${ }^{26}$ According to Table 2 in Murray and Rivers (2015), the share of carbon tax in final prices ranges from $4.4 \%$ for gasoline to $54.7 \%$ for high-heat coal in 2014.

${ }^{27}$ Several studies have taken on the challenge of evaluating environmental tax impacts. Cohen and Tubb (2018) present a meta-analysis of 103 such publications and conclude that there is no statistically significant impact of emissions taxes on productivity. 


\section{References}

1. Abdullah, S. and B. Morley (2014), "Environmental Taxes and Economic Growth: Evidence from Panel Causality Tests", Energy Economics, 42:27-33.

2. Antweiler, W. and S. Gulati (2016), "Frugal Cars or Frugal Drivers? How Carbon and Fuel Taxes Influence the Choice and Use of Cars", Working Paper, University of British Columbia, 35 pages.

3. Beck ,M., N. Rivers, R. Wigle and H. Yonezawa (2015), “Carbon Tax and Revenue Recycling: Impacts on Households in British Columbia", Resource and Energy Economics, 41:40-69.

4. B.C. Ministry of Environment (2010), British Columbia Greenhouse Gas Inventory Report 2008.

5. B.C. Ministry of Environment (2014), British Columbia Greenhouse Gas Inventory Report 2012.

6. B.C. Ministry of Finance (2008), Backgrounder, B.C.'s Revenue-Neutral Carbon Tax.

7. Coglianese, J., L.W. Davis, L. Kilian and J.H. Stock (2017), “Anticipation, Tax Avoidance, and the Price Elasticity of Gasoline Demand", Journal of Applied Econometrics, 32(1):1-15.

8. Cohen, M.A. and A. Tubb (2018), "The Impact of Environmental Regulation on Firm and Country Competitiveness: a Meta-analysis", Journal of Association of Environmental and Resource Economics, 5(2): 371-399.

9. Degiannakis S., G. Filis, and V. Arora (2018), "Oil Prices and Stock Markets: a Review of the Theory and Empirical Evidences", The Energy Journal, 39(5):85-130.

10. Elgie, S. and J. McClay (2013), " BC's Carbon Tax Shift is Working Well after Four Years; Attention Ottawa", Canadian Public Policy, 39(S2):1-10.

11. Eruktu, C. and V. Hildebrand (2018), "Carbon Tax at the Pump in British Columbia and Québec", Canadian Public Policy, 44(2):126-133.

12. Hamilton, J.D. (1996),"This Is What Happened to The Oil Price-Macro Economy Relationship", Journal of Monetary Economics, 38:215-220.

13. Hamilton,J.D.(2011),"Nonlinearities and the Macroeconomic Effects of Oil Prices", Macroeconomic Dynamics, 15(S3): 364-378.

14. Karachi, M.B. (2018),"Oil Prices and State Unemployment Rates", The Energy Journal, 39(3):25-49.

15. Kilian, L. and R.J. Vigfusson (2011),"Are the Responses of the U.S. Economy Asymmetric in energy Price Increases and Decreases", Quantitative Economics, 2:419-453.

16. Kilian, L. and R.J. Vigfusson (2013),"Do Oil Prices Help Forecast U.S. Real GDP? The Role of Nonlinearities and Asymmetries", Journal of Business and Economic Statistics, 31(1):78-93. 
17. Lawley, C. and V. Thivierge (2018), "Refining the Evidence: British Columbia's Carbon Tax and Household Gasoline Consumption", The Energy Journal, 39(2):147-171.

18. Mork, K.A. (1989),"Oil and Macroeconomy When Prices Go up and Down: An Extension of Hamilton's Results", Journal of Political Economy, 97(3): 740-744.

19. Murray B. C. and N. Rivers (2015), “British Columbia's Revenue-Neutral Carbon Tax: A Review of the Latest "Grand Experiment" in Environmental Policy", Energy Policy, 86: 674-683.

20. Porter, M. and C. van der Linde (1995),"Toward a New Conception of the EnvironmentCompetitiveness Relationship", Journal of Economic Perspectives", 9(4): 97-118.

21. Rivers, N. and B. Schaufele (2015), "Salience of Carbon Taxes in the Gasoline Market", Journal of Environmental Economics and Management, 74: 23-36.

21. Statistics Canada, (December 2009), The Supply and Disposition of Refined Petroleum Products In Canada.

22. Yamazaki, A. (2017),"Jobs and Climate Policy: Evidence from British Columbia's Revenue Neutral Carbon Tax", Journal of Environmental Economics and Management, 83: 197-216.

23 Yip, C.M. (2018),"On the Labor Consequences of Environmental Taxes", Journal of Environmental Economics and Management, 89: 136-152. 


\section{Appendix}

\section{Data Sources}

\begin{tabular}{|c|c|}
\hline $\begin{array}{l}\text { Monthly diesel and gasoline average final price } \\
\text { and total taxes in Vancouver, ( } \$ \text { /litre) }\end{array}$ & $\begin{array}{l}\text { Kent Group Ltd., Canada } \\
\text { http://www.kentgroupltd.com/ }\end{array}$ \\
\hline B.C. GDP ( \$2007) & Conference Board of Canada, quarterly \\
\hline B. C. Consumer Price Index (2007=100.0) & $\begin{array}{l}\text { Statistics Canada. Table 18-10-0004-07: Consumer } \\
\text { Price Index (CPI), } 2011 \text { basket, monthly (2002=100). }\end{array}$ \\
\hline B.C. population & $\begin{array}{l}\text { Statistics Canada. Table 17-10-0009-01: Estimates } \\
\text { of population, Canada, provinces and territories, } \\
\text { quarterly (persons). }\end{array}$ \\
\hline Case-Shiller U.S. National Home Price Index & $\begin{array}{l}\text { Federal Reserve Bank of St. Louis } \\
\text { Jan } 2000=100 \text {, monthly, seasonally adjusted } \\
\text { https://fred.stlouisfed.org }\end{array}$ \\
\hline U.S. interest rate & $\begin{array}{l}\text { Federal Reserve Bank of St. Louis } \\
\text { 3-Month Treasury Constant Maturity Rate [GS3M] } \\
\text { https://fred.stlouisfed.org }\end{array}$ \\
\hline U.S. Consumer Price Index $(2010=100.0)$ & $\begin{array}{l}\text { Federal Reserve Bank of St. Louis } \\
\text { Consumer Price Index: Total All Items for the United } \\
\text { States (CPALTT01USM661S) } \\
\text { https://fred.stlouisfed.org }\end{array}$ \\
\hline
\end{tabular}




\begin{abstract}
The province of British Columbia, Canada, introduced a broad-based revenue-neutral carbon tax in July 2008; the rate was set to $\$ 10 /$ tonne of CO2 initially, increased annually by $\$ 5 /$ tonne until 2012 to reach $\$ 30 /$ tonne, and remained at that level until 2017. We use the experience related to this unique initiative to shed some light on the controversy regarding the nature of the relationship between environmental taxes and overall economic activity. In particular, we test whether gasoline and diesel carbon taxes had any impact on GDP changes of the province, either positive or negative. Having found no evidence of asymmetry in the price impact, our analysis is conducted in the context of a standard VAR framework. We conclude that there is no statistically significant effect of carbon taxes on GDP change. The result is supported by tests on slope coefficient estimates as well as via dynamic simulations with and without carbon tax. We also find evidence of complete pass-through of carbon tax into price over time.
\end{abstract}

Key words: Environmental policies, British Columbia carbon tax, tax pass-through, vector autoregression.

JEL Classification: H23, Q43, Q58 